\title{
The efficacy of intracolonic vancomycin for severe Clostridium difficile colitis: a case series
}

\author{
Christine M. Akamine ${ }^{1}$, Michael B. Ing ${ }^{1,2}$, Christian S. Jackson ${ }^{1,3}$ and Lawrence K. Loo ${ }^{1 *}$
}

\begin{abstract}
Background: Clostridium difficile infection (CDI) unresponsive to the standard treatments of metronidazole and oral vancomycin requires aggressive medical management and possible surgical intervention including colectomy. Intracolonic vancomycin therapy has been reported to be particularly promising in the setting of severe CDI in the presence of ileus. This is a descriptive case series exploring the effect of adjunctive intracolonic vancomycin therapy on the morbidity and mortality in patients with moderate to severe CDI.

Methods: A retrospective chart review was conducted on 696 patients with CDI seen at a single institution. Each patient was assigned a severity score and 127 patients with moderate to severe CDI were identified. We describe the clinical presentation, risk factors and hospital course comparing those that received adjunctive intracolonic vancomycin to those that only received standard therapy.

Results: The group that received adjunctive intracolonic vancomycin had higher rates of toxic megacolon, intensive care unit (ICU) admission, and colectomy, and yet maintained a similar mortality rate as the group that received only standard treatment.

Conclusion: The intracolonic vancomycin group experienced more complications but showed a similar mortality rate to the standard therapy group, suggesting that intracolonic vancomycin may impart a protective effect. This study adds further evidence for the need of a randomized controlled study using intracolonic vancomycin as adjunctive therapy in patients presenting with severe CDI.
\end{abstract}

Keywords: Intracolonic vancomycin, Clostridium difficile, Colitis, Mortality, Risk factors

\section{Background}

Clostridium difficile infection (CDI) is a major cause of antibiotic-associated diarrhea worldwide and the incidence of severe colitis is on the rise [1-4]. In 2011, it was estimated that CDI was responsible for almost a half million infections, approximately 29,000 deaths, and almost $\$ 5$ billion in excess health care costs associated with acute care hospitalizations [4]. Severe CDI unresponsive to oral vancomycin and intravenous (IV) metronidazole therapy requires more aggressive medical management and possible surgical intervention [5]. Intracolonic vancomycin, or vancomycin administered

\footnotetext{
*Correspondence: LKLoo@llu.edu; loo.lawrence1@gmail.com

'Department of Medicine, Loma Linda University School of Medicine, 11234

Anderson Street, Loma Linda, CA 92354, USA

Full list of author information is available at the end of the article
}

per rectum, was initially described in the 1980s for use in cases of severe CDI [6-8]. In the case of paralytic ileus or patients unable to take oral medications, intracolonic vancomycin presented a promising alternative method for administering the antibiotic. Since then several groups have published reports of CDI treated with adjunctive intracolonic vancomycin with responses to therapy varying from 57 to $89 \%$ [6, 9-12].

The Loma Linda Veterans Affairs (VA) Healthcare System is a 270 bed facility with approximately 120 acute care beds and is a major teaching affiliate of the Loma Linda University School of Medicine. Between October 2003 and March 2012, there were 696 patients admitted from the outpatient clinics and emergency room to the inpatient service with a confirmed diagnosis of CDI. We used a previously published severity score index [13] to 
identify patients with moderate to severe disease, and then compared the patients who received standard therapy with and without intracolonic vancomycin. The primary aim of our study was to determine whether or not adjunctive treatment with intracolonic vancomycin affected mortality in patients with moderate to severe CDI. We report a descriptive case series performed on 127 patients with moderate to severe CDI.

\section{Methods}

\section{Study population and design}

Between October 2003 and March 2012, 696 patients admitted to the inpatient service with a diagnosis of CDI were entered into an infection control surveillance database using a standardized information form that recorded patient demographics, clinical characteristics and risk factors, hospital course, and outcomes. The case definition of CDI included a patient with the clinical diagnosis of symptomatic diarrhea and one of the following laboratory or diagnostic criteria:

1. A positive enzyme immunoassay (EIA) for Clostridium difficile toxins $\mathrm{A}$ and $\mathrm{B}$ or

2. A positive glutamate dehydrogenase (GDH) assay with reflex confirmatory Clostridium difficile toxin detection by polymerase chain reaction (PCR) or

3. Endoscopic findings consistent with pseudomembranous colitis.

Using a previously validated clinical prediction instrument derived in a VA population, all patients were assigned a Severity Score Index based on the number of clinical and laboratory findings present within $48 \mathrm{~h}$ of the diagnosis of CDI (Table 1) [13, 14]. Severity scores were categorized as mild (0-3 findings), moderate (4-6 findings), or severe (7-9 findings) [14]. Of the 696 total

Table 1 Severity score index for Clostridium difficile infection [14]

\begin{tabular}{ll}
\hline Criteria & Points \\
\hline Altered mental status (documented in the record) & 1 \\
Abdominal pain or distension (documented in the record) & 1 \\
Leukocytosis (WBC $>20,000$ cells $/ \mathrm{mm}^{3}$ ) or leukopenia & 1 \\
$(<1500)$ or $>10 \%$ bands & 1 \\
Hypoalbuminemia ( $<2.5 \mathrm{mg} / \mathrm{dL}$ ) & 1 \\
Ascites or colitis (documented by imaging) & 1 \\
Hypotension (MAP $<65 \mathrm{~mm} \mathrm{Hg})$ & 1 \\
Fever ( $\left.\geq 101^{\circ} \mathrm{F}\right)$ & 1 \\
Tachycardia $(\geq 110$ bpm) & 1 \\
Admission or transfer to ICU
\end{tabular}

Interpretation: 0-3 is mild disease; 4-6 is moderate disease; 7-9 is severe disease

WBC white blood cells, MAP mean arterial pressure, ICU intensive care unit patients, 569 patients with a severity score of 3 or less were determined to have mild CDI and were excluded from this study. This report focuses on the 127 remaining patients with moderate (108) to severe (19) CDI. A total of 26 patients received treatment that included intracolonic vancomycin while 101 patients received treatment without intracolonic vancomycin.

\section{Data collection and patient outcomes}

Demographic information included age, gender, and dates of hospital admission. Antibiotics and other medications taken 8 weeks prior to the diagnosis of CDI were recorded. Clinical symptoms and risk factors such as previous CDI within the past 12 months, ICU admission or transfer, presence of comorbid medical conditions, and recent vancomycin resistant enterococcus (VRE) or methicillin resistant Staphylococcus aureus (MRSA) infection and/or colonization were recorded. Laboratory data including a complete blood cell count $(\mathrm{CBC})$, albumin, blood urea nitrogen (BUN), creatinine, albumin, and coagulation studies (PT, PTT, INR) were collected within $72 \mathrm{~h}$ of the diagnosis of CDI.

Charts of all patients enrolled in the study were reviewed for at least 90 days after diagnosis of CDI in order to determine outcomes. Outcomes were categorized as ICU admission, development of toxic megacolon, colectomy, and/or death.

\section{Statistical analysis}

Differences between groups were analyzed using chisquare, Fisher's exact and unpaired t-tests as approprite. Because of the exploratory nature of the study and multiple hypotheses testing, a $p$-value $\leq 0.01$, rather than a $p \leq 0.05$, was chosen to determine statistical significance [15].

\section{Results}

Baseline demographics, clinical characteristics and risk factors

Demographics, baseline characteristics, and risk factors of the patients in the study are summarized in Table 2. The majority of the patients were male $(84.3 \%)$, and the mean age was 68.5 years. The group that received intracolonic vancomycin had higher severity score indices on average compared to those who did not receive intracolonic vancomycin, although this did not meet the predetermined significance level $(p=0.03)$. The two groups had similar frequencies of major comorbidities and admission medications. Patients who received intracolonic vancomycin were more likely to have had a history of CDI prior to hospitalization, although this difference was not statistically significant $(p=0.06)$. 
Table 2 Comparison of Clostridium difficile infected patients' presentations between those who were treated with adjunctive intracolonic vancomycin and those who received therapy without intracolonic vancomycin

\begin{tabular}{|c|c|c|c|}
\hline & $\begin{array}{l}\text { Therapy with adjunctive intracolonic } \\
\text { vancomycin } \\
\text { No. (\%) or average } \pm \text { s.d. }\end{array}$ & $\begin{array}{l}\text { Therapy without intracolonic } \\
\text { vancomycin } \\
\text { No. (\%) or average } \pm \text { s.d. }\end{array}$ & $P$ value* \\
\hline Total Number & $26(20.5 \%)$ & $101(79.5 \%)$ & \\
\hline Severe Disease & $7(26.9 \%)$ & $12(11.9 \%)$ & 0.11 \\
\hline Moderate Disease & $19(73.1 \%)$ & $89(88.1 \%)$ & 0.70 \\
\hline Age (years + SD) & $67 \pm 8$ & $70 \pm 13$ & 0.31 \\
\hline Male Sex & $25(96.2 \%)$ & $82(81.2 \%)$ & 0.07 \\
\hline Average Severity Score Index for Total Group & $5.69 \pm 1.4$ & $5.02 \pm 1.0$ & 0.03 \\
\hline Severe Disease & $7.58 \pm 0.98$ & $7.08 \pm 0.29$ & 0.24 \\
\hline Moderate Disease & $5.00+0.75$ & $4.74+0.75$ & 0.17 \\
\hline \multicolumn{4}{|l|}{ Past Medical History } \\
\hline Recent surgery within last 6 weeks & $9(34.6 \%)$ & $25(24.7 \%)$ & 0.31 \\
\hline History of CDI within the past 12 months & 7 (26.9 \%) & $11(10.9 \%)$ & 0.06 \\
\hline \multicolumn{4}{|l|}{ Comorbidities } \\
\hline Diabetes mellitus & $13(50.0 \%)$ & $34(33.7 \%)$ & 0.12 \\
\hline Coronary artery disease & $9(34.7 \%)$ & $26(25.7 \%)$ & 0.37 \\
\hline Congestive heart failure & 7 (15.4\%) & $18(17.8 \%)$ & 0.30 \\
\hline COPD & $9(34.6 \%)$ & $25(24.8 \%)$ & 0.31 \\
\hline Malignancy & $8(20.7 \%)$ & 30 (29.7 \%) & 0.92 \\
\hline Cirrhosis & $1(3.8 \%)$ & $5(5.0 \%)$ & 1.00 \\
\hline \multicolumn{4}{|l|}{ Admission Medications } \\
\hline Proton pump inhibitors & $13(68.4 \%)$ & $62(57.4 \%)$ & 0.45 \\
\hline Aspirin & $8(42.1 \%)$ & $36(34.0 \%)$ & 0.46 \\
\hline H2 blockers & $4(21.1 \%)$ & $35(32.4 \%)$ & 0.42 \\
\hline Corticosteroids & $3(15.8 \%)$ & 33 (30.1%) & 0.27 \\
\hline \multicolumn{4}{|c|}{ Laboratory Values within the first $72 \mathrm{~h}$ of the diagnosis of CDI } \\
\hline WBC (cells $/ \mathrm{mm}^{3}$ ) & $27.2 \pm 14.9$ & $24.1 \pm 16.9$ & 0.36 \\
\hline $\mathrm{Hgb}(\mathrm{g} / \mathrm{L})$ & $10.1+1.9$ & $10.0 \pm 3.1$ & 0.84 \\
\hline Albumin (g/dL) & $1.7 \pm 0.5$ & $1.8 \pm 0.5$ & 0.55 \\
\hline BUN (mg/dL) & $46.4 \pm 28.2$ & $42.3 \pm 33.0$ & 0.51 \\
\hline Creatinine (mg/dL) & $2.2 \pm 1.8$ & $2.2 \pm 1.8$ & 0.97 \\
\hline Prior antibiotics within 8 weeks of diagnosis of CDI & $24(92.3 \%)$ & $94(93.1 \%)$ & 0.76 \\
\hline
\end{tabular}

*Because of multiple hypotheses testing, a $p$ value $\leq 0.01$ determined statistical significance

$S D$ standard deviation, CDI Clostridium difficile infection, COPD chronic obstructive pulmonary disease, WBC white blood cell, $H g$ hemoglobin, $B U N$ blood urea nitrogen

Admission laboratory values were similar and both groups presented with marked leukocytosis, impaired renal function, and hypoalbuminemia reflective of the severity of their infection (Table 2).

Almost all of the patients had received additional antibiotics within 8 weeks of CDI diagnosis, with the most common exposures to penicillins, cephalosporins and quinolones. There were no differences noted in the predisposing antibiotic classes between the two groups.

\section{Hospital course and outcomes}

Table 3 presents the hospital course and outcomes of the 127 patients with moderate to severe CDI. The patients who received intracolonic vancomycin had a longer period of hospitalization compared with the patients who did not receive intracolonic vancomycin, (39.1 \pm 30.6 days vs. $27.1 \pm 33.3$ days), although this difference was not statistically significant $(p=0.09)$. There was an increased incidence of recent VRE and MRSA infections 
Table 3 Hospital course and outcomes of Clostridium difficile infected patients who were treated with therapy including adjunctive intracolonic vancomycin compared to those who received therapy without intracolonic vancomycin

\begin{tabular}{|c|c|c|c|}
\hline & $\begin{array}{l}\text { Therapy with adjunctive intracolonic } \\
\text { vancomycin } \\
\text { No. (\%) or average } \pm \text { s.d. }\end{array}$ & $\begin{array}{l}\text { Therapy without intracolonic } \\
\text { vancomycin } \\
\text { No. (\%) or average } \pm \text { s.d. }\end{array}$ & $P$ value* \\
\hline Total Number & $26(20.5 \%)$ & $101(79.5 \%)$ & \\
\hline Average Severity Score Index (range 0-9) & $5.69 \pm 1.4$ & $5.02 \pm 1.0$ & 0.03 \\
\hline Length of hospital stay (days): average + SD & $39.1 \pm 30.6$ & $27.1 \pm 33.3$ & 0.09 \\
\hline Death & $10(38.5)$ & 39 (38.6 \%) & 1.00 \\
\hline Oral vancomycin & $21(80.8 \%)$ & $44(43.6 \%)$ & 0.0008 \\
\hline Oral metronidazole & $13(50.0 \%)$ & 76 (75.2 \%) & 0.012 \\
\hline IV metronidazole & $25(96.2 \%)$ & $45(44.6 \%)$ & $<0.0001$ \\
\hline Admission to or transfer to the ICU & $24(92.3 \%)$ & $70(69.3 \%)$ & 0.022 \\
\hline Fever $\left(>101^{\circ} \mathrm{F}\right)$ & $10(38.5 \%)$ & 37 (33.7 \%) & 0.86 \\
\hline lleus & $12(46.2 \%)$ & $29(28.7 \%)$ & 0.10 \\
\hline Toxic megacolon & $9(34.6 \%)$ & $4(4.0 \%)$ & $<0.0001$ \\
\hline Colectomy & $4(15.4 \%)$ & $1(1.0 \%)$ & 0.006 \\
\hline Recent VRE infection and/or colonization & $7(26.9 \%)$ & $6(5.9 \%)$ & 0.005 \\
\hline Recent MRSA infection and/or colonization & $10(38.5 \%)$ & $14(13.7 \%)$ & 0.007 \\
\hline
\end{tabular}

*Because of multiple hypotheses testing, a $p$ value $\leq 0.01$ determined statistical significance

$S D$ standard deviation, IV intravenous, ICU intensive care unit, VRE vancomycin resistant enterococcus, MRSA methicillin resistant Staphylococcus aureus

or colonizations in the group that received intracolonic vancomycin compared to the group who received standard treatment without intracolonic vancomycin, $p=$ $0.005, p=0.007$ respectively (Table 3 ).

More patients in the intracolonic vancomycin group also received IV metronidazole and oral vancomycin, while the majority of patients in the non-intracolonic vancomycin treatment group received oral metronidazole (Table 3). The doses of intracolonic vancomycin ranged from $0.25 \mathrm{~g}$ every $24 \mathrm{~h}$ to $1 \mathrm{~g}$ every $6 \mathrm{~h}$, with the most common dose administered being $500 \mathrm{mg}$ every $6 \mathrm{~h}$ (16 patients). This variation in doses was similar to other large case series reported in the medical literature (Table 4). In our study, the duration of intracolonic vancomycin was quite variable ranging from 1 to 34 days with a median of 7 days and an interquartile range of 2 -10 days.

\section{Discussion}

We present a retrospective study of 127 patients describing the utility of treating severe CDI using intracolonic vancomycin. To our knowledge this is the second largest case series published to date [6, 9-11] (Table 4).

In this study of patients with moderate to severe CDI, those treated with intracolonic vancomycin were critically ill since more than $90 \%$ were admitted into the ICU and the average length of hospital stay was almost 40 days. This group had a higher incidence of toxic megacolon, which is a serious and life-threatening condition associated with a high mortality rate and systemic toxicity $[16,17]$. Additionally this group underwent a greater number of colectomies, a therapy that is often reserved for severe refractory disease [17]. Despite having a greater number of Clostridium difficile-associated severe complications and a higher severity score (5.69 vs 5.02 ), the group that received adjunctive intracolonic vancomycin maintained a similar mortality rate as the group that received standard treatment without intracolonic vancomycin (38.5 vs $38.6 \%$ ). The severity score index that had been previously derived and validated in a VA population would have predicted a mortality closer to $50 \%[13,14]$. This may suggest a protective role of intracolonic vancomycin.

In our study, patients treated with intracolonic vancomycin were also more likely to be infected or colonized with MRSA and VRE. The predominance of VRE and MRSA in the group that received intracolonic vancomycin may be demonstrative of excessive antibiotic use predisposing to severe CDI [18]. Antibiotic overuse is a major cause of severe CDI $[18,19]$. Non-essential antibiotics can eliminate protective colonic flora and predispose to colonization and infection by virulent strains of Clostridium difficile [20]. VRE and MRSA are established markers of antimicrobial overuse and patients diagnosed with VRE are at greater risk for developing recurrent CDI [21]. Another explanation for our observation is that CDI has been shown to be a common coinfection in patients diagnosed with VRE secondary to the use vancomycin and metronidazole and prior use of metronidazole [22]. There have been a number of other 
Table 4 Large case series reporting Clostridium difficile infections (CDI) treated with intracolonic vancomycin per rectum

\begin{tabular}{|c|c|c|c|c|}
\hline Reference & Number of patients & Hospital setting & Co-morbidities and outcomes & $\begin{array}{l}\text { Intracolonic vancomycin } \\
\text { dosing regimens per rectum }\end{array}$ \\
\hline Current Series & $\begin{array}{l}26 \text { patients over } 10 \text { years: } \\
2003-2012\end{array}$ & $\begin{array}{l}\text { Single VA center, Loma } \\
\text { Linda, CA }\end{array}$ & $\begin{array}{l}\text { Median age }=69 \text { years } \\
\text { Severity Score Index (range 0-9) = } 5.2 \\
\text { suggestive of "moderate" CDI } \\
\text { Mean WBC }=27 \mathrm{k} \\
16 \text { patients survived, } 10 \text { died }\end{array}$ & $\begin{array}{l}\text { Variable doses ranging from } \\
0.25 \mathrm{~g} \text { q24 h to } 1 \mathrm{~g} \text { q6h }- \text { most } \\
\text { common dose } 500 \mathrm{mg} \text { q6h }\end{array}$ \\
\hline $\begin{array}{l}\text { Saffouri } \\
\text { Gastroenterology } 2014 \text { [11] }\end{array}$ & $\begin{array}{l}17 \text { patients over } 7 \text { years: } \\
2005-2012 \text {. }\end{array}$ & $\begin{array}{l}\text { Single tertiary care } \\
\text { teaching hospital, } \\
\text { Rochester, MN }\end{array}$ & $\begin{array}{l}\text { Median age }=70 \text { years } \\
\text { "Severe" CDI (WBC }>15 \mathrm{k} \text { or serum } \\
\text { creatinine }>1.5 \times \text { baseline) or } \\
\text { "Severe-complicated" CDI (i.e., } \\
\text { shock, hypotension, ileus., toxic } \\
\text { megacolon or ICU admission) } \\
16 \text { patients survived, } 1 \text { died }\end{array}$ & $\begin{array}{l}\text { Variable doses ranging from } \\
0.25 \mathrm{~g} \text { q6 to } 1 \mathrm{~g} \mathrm{q} 6 \text { - most } \\
\text { common dose } 500 \mathrm{mg} \text { q6h }\end{array}$ \\
\hline $\begin{array}{l}\text { Kim } \\
\text { Surg Infect } 2013 \text { [10] }\end{array}$ & $\begin{array}{l}47 \text { patients over } \\
2.75 \text { years: } 2007-2009\end{array}$ & $\begin{array}{l}\text { Single inner-city hospital, } \\
\text { Bronx, NY }\end{array}$ & $\begin{array}{l}\text { Mean age }=65 \text { years } \\
\text { "Severe" CDI (any of the following: } \\
\text { WBC }>15 \mathrm{k} \text {, abdominal tenderness, } \\
\text { acidosis) } \\
\text { Mean WBC = } 27 \mathrm{k} \\
37 \text { patients survived, } 10 \text { died }\end{array}$ & All received $1 \mathrm{~g}$ q6h \\
\hline $\begin{array}{l}\text { Apiusarnthanarkak } \\
\text { CID } 2002 \text { [6] }\end{array}$ & $\begin{array}{l}9 \text { cases over } 3 \text { years over } \\
3.5 \text { years: } 1998-2001\end{array}$ & $\begin{array}{l}\text { Single tertiary care } \\
\text { teaching hospital, St. } \\
\text { Louis, MO }\end{array}$ & $\begin{array}{l}\text { Median age }=65 \text { years } \\
\text { Mean APACHE II score }=18 \\
\text { (range } 12-26 \text { ) } \\
\text { Median WBC }=24 \mathrm{k} \\
8 \text { patients survived, } 1 \text { died }\end{array}$ & $\begin{array}{l}\text { Variable doses ranging from } \\
0.5 \mathrm{~g} \text { q4h to } 1 \mathrm{~g} \mathrm{q} 12 \mathrm{~h}-\text { most } \\
\text { common dose } 1 \mathrm{~g} \mathrm{q} 12 \mathrm{~h}\end{array}$ \\
\hline $\begin{array}{l}\text { Shetler } \\
\text { Surg Endosc } 2001 \text { [9] }\end{array}$ & 8 cases & $\begin{array}{l}\text { Single VA center, Palo } \\
\text { Alto, CA }\end{array}$ & $\begin{array}{l}\text { Mean age }=70 \text { years } \\
\text { "Severe" CDI all with ileus } \\
\text { and toxic megacolon } \\
\text { Median WBC }=24 \mathrm{k} \\
3 \text { patients survived, } 4 \text { died }\end{array}$ & All received $0.25 \mathrm{~g} q 6 \mathrm{~h}$ \\
\hline
\end{tabular}

hypotheses for this relationship, such as the sharing of common risk factors between the two groups [23], treatment with broad spectrum antibiotics for VRE, and use of vancomycin for the treatment of CDI.

Current practice guidelines for the initial management of CDI recommend stratifying patients into mild, moderate and severe CDI $[1-3,24]$. However, no single classification has been validated in a broad population or achieved national acceptance for this purpose $[25,26]$. We chose to use the severity score index developed by Velazquez-Gomez [14] and validated by Toro [13] because these studies were done in a VA population similar to ours. However, this index would have predicted an approximate $50 \%$ and $100 \%$ mortality in moderate and severe $\mathrm{CDI}$ groups respectively, which is in contrast to the $39 \%$ observed for both groups in our study. One explanation for this discrepancy is that the original prediction rule may not be applicable to other populations since it was derived from a small sample of 101 patients and validated in another small sample of 54 patients, both from the same single institution [27]. Another possibility is that because the intracolonic vancomycin group was critically ill with more comorbidities, their physicians were more likely to prescribe intracolonic vancomycin secondary to non-response from oral antibiotics. This confounding by indication is a well known bias of retrospective studies.
Current guidelines vary in their recommendations for the initial treatment of severe CDI and the role of intracolonic vancomycin. The Society for Healthcare Epidemiology of America (SHEA) and Infectious Diseases Society of America (IDSA) [2] recommend, besides oral vancomycin and IV metronidazole, "if complete ileus consider (italics added by the authors) adding rectal installation of vancomycin." Gastrointestinal guidelines [1] recommend for CDI patients complicated with ileus or toxic colitis and/or significant abdominal distention, the "treatment of choice" is oral and per rectum vancomycin plus IV metronidazole. The European Society of Clinical Microbiology and Infectious Diseases [3] recommend one of 3 regimens for "severe, and/or complicated or refractory CDI": IV metronidazole plus per rectum vancomycin or IV metronidazole plus oral vancomycin or IV tigecycline. The use of rectal vancomycin is based on low quality evidence, mostly case series and expert opinion [1-3]. In our series, many of the cases occurred before the publication of the current guidelines. As with most other case series described in the literature (see Table 4), the dosage of intracolonic vancomycin varied from 0.25 to $1 \mathrm{~g}$ every $6 \mathrm{~h}$ with the most common dosage being $500 \mathrm{mg}$ every $6 \mathrm{~h}$. The latter dose and frequency reflect current practice guidelines recommendations, although this is based on low quality evidence $[1,3]$. The 
duration of use in our study was also quite variable ranging from 1 to 34 days with a median of 7 days. The authors were unable to find the duration of intracolonic vancomycin use in most other published case series listed in Table 4. Current guidelines also vary with their recommendations for duration of use ranging from 10 days [3] to "until the patient improves" [1], but in both situations this is also based on low quality evidence.

Finally, other potential therapies for CDI not used in our case series include the use of intravenous immunoglobulin (IVIG) and Fecal Microbiota Transplantation (FMT). In recent years there has been a renewed focus on the use of Fecal Microbiota Transplantation (FMT) for the treatment of recurrent CDI. The current data on FMT for the treatment of severe CDI is limited only to case reports or small case series $[28,29]$. It remains to be seen how FMT will fit into the treatment of severe CDI.

Compared to other case series, the strengths of our study include the consecutive identification of all patients with CDI based on our hospital's infection control surveillance during the time period studied, systematic collection of information from charts using a standardized form, application of a single severity index that stratified patients into comparable risk groups, and complete follow-up to at least 90 days after the diagnosis of CDI was made to record complications and outcomes.

The limitations of our study include those inherent to most retrospective studies including selection bias, recall bias, and confounding by indication. The population studied comes from a single institution, focusing on a veteran population, which may also limit this study's application to more diverse populations. As noted in Table 3, although the severity score indices between the two groups were not statistically significant, the baseline therapy between the two groups differed significantly. The non-intracolonic vancomycin group received more oral metronidazole compared with the intracolonic vancomycin group, which received more IV metrondizaole and oral vancomycin. Since this was a retrospective study over 10 years, the "standard" of care evolved and primary care providers varied in their treatment approaches which has the potential to confound the study results. As noted in Table 4, the clinical indications for intracolonic vancomycin, doses and duration of uses, and outcomes vary significantly in this study and among other reported cases series in the literature. Data differentiating PCR-positive, toxinnegative patients from PCR-positive, toxin-positive patients were not collected and the specific strain of CDI for each case was also not available. Finally, the standardized information form recorded only all-cause 90 day mortality without a specified cause of death.

\section{Conclusion}

Intracolonic vancomycin is a promising adjunctive therapy for patients with severe CDI, which carries a high mortality rate. In our retrospective study, despite having a higher incidence of Clostridium difficile-associated severe complications and being more critically ill, the group that received adjunctive intracolonic vancomycin demonstrated a similar mortality rate compared to the group that did not receive this therapy. While intriguing to hypothesize that intracolonic vancomycin may reduce the morbidity and mortality of severe CDI, only a prospective randomized controlled trial can determine the true causality of the effectiveness of this potentially important adjunctive therapy.

\section{Abbreviations \\ CDI, Clostridium difficile infection; EIA, enzyme immunoassay; FMT, fecal microbiota transplantation; $\mathrm{GDH}$, glutamate dehydrogenase; ICU, intensive care unit; IDSA, Infectious Diseases Society of America; PCR, polymerase chain reaction; SHEA, Society for Healthcare Epidemiology of America; VA, Veterans Affairs; VRE, vancomycin resistant enterococcus}

\section{Acknowledgments}

None.

\section{Funding}

There was no funding for this investigator initiated project other than the general support of the authors' time from the VA Loma Linda Healthcare System and the Department of Medicine of the Loma Linda University School of Medicine.

\section{Availability of data and materials}

In accordance with the VA Loma Linda Healthcare System's Institutional Review Board's policies, the data for this study is maintained on research servers at the VA Loma Linda Medical Center in accordance with VA records retention policy, which requires records to be maintained for 6 years from the close of the study. If access to this data is needed, please contact the VA Administrative Office for Research at 1-909-583-6050.

\section{Authors' contributions}

CMA, MBI, and CSJ conceived of the idea for the study. CMA collected the data. LKL analyzed the data. CMA drafted the initial manuscript and all authors contributed to the literature review, intellectual content, revisions and approval of the final submission.

\section{Authors' information}

CMA is currently a resident in the categorical Internal Medicine residency at the Loma Linda University Medical Center, Loma Linda, California. $\mathrm{MBI}$ is Chief of the Section of Infectious Diseases at the VA Loma Linda Healthcare System and is Associate Professor of Medicine, Department of Medicine, Loma Linda University School of Medicine, Loma Linda, California. CSJ is Chief of the Section of Gastroenterology at the VA Loma Linda Healthcare System and is Assistant Professor of Medicine, Department of Medicine, Loma Linda University School of Medicine, Loma Linda, California. LKL is Vice-chair of Education and Faculty Development and Professor of Medicine, Departments of Medicine and Medical Education, Loma Linda University School of Medicine, Loma Linda, California.

\section{Competing interests}

The authors declare that they have no competing interests.

\section{Ethics approval and consent to participate}

In 2007, the VA Loma Linda Healthcare System's Institutional Review Board prospectively reviewed and determined this study was conducted in accord with appropriate ethical standards. Consent for publication was not applicable. 


\section{Author details}

'Department of Medicine, Loma Linda University School of Medicine, 11234 Anderson Street, Loma Linda, CA 92354, USA. ${ }^{2}$ Section of Infectious Disease, VA Loma Linda Healthcare System, 11201 Benton Street, Loma Linda, CA 92357, USA. ${ }^{3}$ Section of Gastroenterology, VA Loma Linda Healthcare System, 11201 Benton Street, Loma Linda, CA 92357, USA.

Received: 29 July 2015 Accepted: 16 June 2016

\section{Published online: 07 July 2016}

\section{References}

1. Surawicz CM, Brandt $\sqcup$, Binion DG, Ananthakrishnan AN, Curry SR, Gilligan $\mathrm{PH}$, et al. Guidelines for diagnosis, treatment, and prevention of Clostridium difficile infections. Am J Gastroenterol. 2013;108(4):478-98. quiz 499.

2. Cohen SH, Gerding DN, Johnson S, Kelly CP, Loo VG, McDonald LC, et al. Clinical practice guidelines for Clostridium difficile infection in adults: 2010 update by the society for healthcare epidemiology of America (SHEA) and the infectious diseases society of America (IDSA). Infect Control Hosp Epidemiol. 2010;31(5):431-55.

3. Debaset SB, Bauer MP, Juijper EJ, European Society of Clinical Microbiology and Infectious Diseases. European Society of Clinical Microbiology and Infectious Diseases: update of the treatment guideline document for Clostridium difficile infection. Clin Microbiol Infect. 2014;20(Supple 2):1-26.

4. Lessa FC, Mu Y, Bamberg WM, et al. Burden of Clostridium difficile infection in the United States. N Engl J Med. 2015;372(9):825-34.

5. Apisarnthanarak A, Mundy LM. Intracolonic vancomycin for adjunctive treatment of severe Clostridium difficile colitis: indications and precautions. J Infect Dis Antimicrob Agents. 2005;22(1):21.

6. Apisarnthanarak A, Razavi B, Mundy LM. Adjunctive intracolonic vancomycin for severe Clostridium difficile colitis: case series and review of the literature. Clin Infect Dis. 2002;35(6):690-6.

7. George WL, Rolfe RD, Finegold SM. Treatment and prevention of antimicrobial agent-induced colitis and diarrhae. Gastroenterology. 1980; 79(2):366-72.

8. Griebie M, Adams GL. Clostridium difficile colitis following head and neck surgery. Report of cases. Arch Otolaryngol. 1985;111(8):550-3.

9. Shetler K, Nieuwenhuis R, Wren SM, Triadafilopoulos G. Decompressive colonoscopy with intracolonic vancomycin administration for the treatment of severe pseudomembranous colitis. Surg Endosc. 2001;15(7):653-9.

10. Kim PK, Huh HC, Cohen HW, Feinberg EJ, Ahmad S, Coyle C, et al. Intracolonic vancomycin for severe Clostridium difficile colitis. Surg Infect. 2013;14(6):532-9.

11. Saffouri G, Khanna S, Estes L, Pardi D. Outcomes from rectal vancomycin therapy in patients with Clostridium difficile infection. Am J Gastroenterol. 2014;109(6):924-5.

12. Olson MM, Shanholtzer CJ, Lee JT, Gerding DN. Ten years of prospective Clostridium difficile-associated disease surveillance and treatment at the Minneapolis VA Medical Center, 1982-1991. Infect Control Hosp Epidemiol. 1994;15(6):371-81.

13. Toro DH, Amaral-Mojica KM, Rocha-Rodriguez R, Gutierrez-Nuñez J. An innovative severity score index for Clostridium difficile infection: a prospective study. Infect Dis Clin Pract. 2011;19(5):336-9.

14. Velazquez-Gomez I, Rocha-Rodriguez R, Toro DH, Gutierrez-Nuñez J, Gonzalez G, Saavedra S. A severity score index for Clostridium difficile infection. Infect Dis Clin Pract. 2008;16(6):376-8.

15. Lang TA, Secic M. How to report statistics in medicine. Annotated guidelines for authors, editors, and reviewers. 2nd ed. Philadelphia: American College of Physicians; 2006.

16. Trudel JL, Deschênes M, Mayrand S, Barkun AN. Toxic megacolon complicating pseudomembranous enterocolitis. Dis Colon Rectum. 1995; 38(10):1033-8

17. Berman L, Carling T, Fitzgerald TN, Bell RL, Duffy AJ, Longo WE, et al. Defining surgical therapy for pseudomembranous colitis with toxic megacolon. J Clin Gastroenterol. 2008;42(5):476-80.

18. Lai C-C, Chu C-C, Cheng A, Huang Y-T, Hsueh P-R. Correlation between antimicrobial consumption and incidence of health-care-associated infections due to methicillin-resistant Staphylococcus aureus and vancomycin-resistant enterococci at a university hospital in Taiwan from 2000 to 2010. J Microbiol Immunol Infect. 2015;48(4):431-6.

19. Pakyz $A L$, Jawahar $R$, Wang $Q$, Harpe SE. Medication risk factors associated with healthcare-associated Clostridium difficile infection: a multilevel model case-control study among 64 US academic medical centres. J Antimicrob Chemother. 2014:69(4):1127-31.

20. Loo VG, Bourgault A-M, Poirier L, Lamothe F, Michaud S, Turgeon N, et al. Host and pathogen factors for Clostridium difficile infection and colonization. N Engl J Med. 2011;365(18):1693-703.

21. Choi HK, Kim KH, Lee SH, Lee SJ. Risk factors for recurrence of Clostridium difficile infection: effect of vancomycin-resistant enterococci colonization. J Korean Med Sci. 2011;26(7):859-64.

22. Poduval RD, Kamath RP, Corpuz M, Norkus EP, Pitchumoni CS. Clostridium difficile and vancomycin-resistant enterococcus: the new nosocomial alliance. Am J Gastroenterol. 2000:95(12):3513-5.

23. Gerding DN. Is there a relationship between vancomycin-resistant enterococcal infection and Clostridium difficile infection? Clin Infect Dis. 1997;25 Suppl 2:S206-10.

24. Bagdasarian N, Rao K, Malani PN. Diagnosis and treatment of Clostridium difficile in adults: a systematic review. JAMA. 2015;313(4):398-408.

25. Abou Chakra CN, Pepin J, Valiquette L. Prediction tools for unfavourable outcomes in Clostridium difficile infection: a systematic review. PLoS One. 2012;7(1):e30258.

26. Fujitani S, George WL, Murthy AR. Comparison of clinical severity score indices for Clostridium difficile infection. Infect Control Hosp Epidemiol. 2011:32(3):220-8.

27. McGinn TG, Guyatt GH, Wyer PC, Naylor CD, Stiell IG, Richardson WS. Users' guides to the medical literature: XXIl: how to use articles about clinical decision rules. Evidence-Based Medicine Working Group. JAMA. 2000;284(1):79-84.

28. Trubiano JA, Gardiner B, Kwong JC, Ward P, Testro AG, Charles PGP. Faecal microbiota transplantation for severe Clostridium difficile infection in the intensive care unit. Eur J Gastroenterol Hepatol. 2013;25(2):255-7.

29. Gallegos-Orozco JF, Paskvan-Gawryletz CD, Gurudu SR, Orenstein R. Successful colonoscopic fecal transplant for severe acute Clostridium difficile pseudomembranous colitis. Rev Gastroenterol Méx. 2012;77(1):40-2.

\section{Submit your next manuscript to BioMed Central and we will help you at every step:}

- We accept pre-submission inquiries

- Our selector tool helps you to find the most relevant journal

- We provide round the clock customer support

- Convenient online submission

- Thorough peer review

- Inclusion in PubMed and all major indexing services

- Maximum visibility for your research

Submit your manuscript at www.biomedcentral.com/submit 